\title{
Las obsesiones corporales de Carmen Lyra entre la mirada biopolítica, el saber literario y las metáforas del poder
}

\section{Dennis Arias Mora ${ }^{1}$}

Recepción: 6 de octubre de 2013 / Aprobación: 2 de diciembre de 2013

\section{Resumen}

El artículo analiza el vínculo entre la escritora Carmen Lyra y el biopoder. En la primera mitad del siglo XX, las campañas gubernamentales por la higiene, el saneamiento de la capital y la reducción de la mortalidad infantil conllevaron una intervención minuciosa de los cuerpos, especialmente de mujeres y niños. Se muestra el papel de la literatura al interior del biopoder, se distingue la escritura de Lyra respecto a la mirada jerárquica de médicos y literatos sobre los cuerpos, pero la presenta también como parte del biopoder al construir sus cultos heroicos. Para ello se contrasta la obra de Lyra y sus entrevistas en el periódico comunista Trabajo, con la narrativa médica y literaria. El artículo otorga a la literatura un estatuto de saber, por lo cual aparece no como referente ilustrativo del pasado, sino como un discurso biopolítico que provee de metáforas al biopoder.

\section{Palabras clave}

Biopolítica, cuerpo, metáfora, saber literario, Carmen Lyra

\section{Abstract}

The article analyzes the connection between the writer Carmen Lyra and the biopower. During the first half of the twentieth century, government campaigns for hygiene, sanitation of the capital city and the reduction of child mortality entailed a thorough intervention of bodies, especially those of women and children. The article shows the role of literature inside the biopower, distinguishing the writing of Lyra from the hierarchical gaze of physicians and other writers on the bodies, but it also shows Lyra as a creator of heroic cults for the biopower. The work and interviews of Lyra in the communist newspaper Trabajo will be contrasted with the medical and literary narratives. The article gives literature the status of knowledge, for which it does not appear as an illustrative reference to the past, but as another biopolitical discourse providing metaphors for the biopower.

1 Costarricense. Doctor en Historia por la Universidad Libre de Berlín, Alemania. Profesor de la Escuela de Historia, Universidad de Costa Rica, Costa Rica. Correo electrónico: dennarm@yahoo.de 


\section{Keywords}

Biopolitics, body, metaphor, literary knowledge, Carmen Lyra

\section{Resumo}

O artigo analisa o vínculo entre a escritora Carmen Lyra e o biopoder. Na primeira metade do século XX, as campanhas governamentais de higiene, saneamento da capital e redução da mortalidade infantil implicaram em uma intervenção minuciosa dos corpos, especialmente de mulheres e crianças. Mostra-se o papel da literatura no interior do biopoder, se diferencia a escritura de Lyra em relação à visão hierárquica de médicos e estudiosos sobre os corpos, porém essa é apresentada também como parte do biopoder ao construir seus cultos heroicos. Para isso, se contrasta a obra de Lyra e suas entrevistas ao jornal comunista Trabajo, com a narrativa médica e literária. O artigo outorga à literatura um estatuto de saber, através do qual aparece não como referente ilustrativo do passado, senão como um discurso biopolítico que provê de metáforas ao biopoder.

\section{Palavras chave}

Biopolítica, corpo, metáfora, saber literário, Carmen Lyra

"Las cárceles están llenas de pies que casi siempre han andado descalzos o mal calzados". Carmen Lyra, 1935.

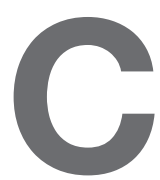
erca de 1949, la educadora comunista Luisa González (19041999) recordaba la ironía que caracterizaba a su compañera, la escritora Carmen Lyra (1888-1949), irónica incluso consigo misma; sobre su seudónimo decía: "¡Es muy lindo! Pero imagínese qué desilusión se llevan las gentes cuando al conocerme van viendo esta negrilla pelona y con semejante ñata: claro que no le hago juego con este seudónimo tan sonoro" (González, 2006, 118). No era una referencia aislada; desde los años veinte, otros testimonios (respetuosa o torpemente) aludieron al físico de Lyra (Ethal, 1923, 3-4; Salas, 1998, 29) como ajeno al canon estético que la industria de la moda, religiosos y periodistas (Alvarenga, 2012, 145-170), así como médicos también, crearon sobre los cuerpos de las mujeres desde fines del siglo XIX. El episodio, posiblemente más dramático de lo que la ironía insinúa, permite pensar ciertos aspectos del lugar de escritura de esta reconocida intelectual; como podrá verse, gran parte de su obra literaria y periodística se recubre de un motivo constante: el cuerpo, pocas veces esbelto, la mayoría de las veces herido, maltratado, deforme o mutilado. No quiere decir que pueda establecerse una asociación simple entre la propia corporalidad y la escritura, sino más bien que el lugar del escribir es histórico, y por tanto compuesto de diversos 
procesos políticos y culturales (Goschler, 2005) que marcaron la experiencia de los cuerpos, las mujeres y el poder en el siglo XX.

¿En qué registros del pasado se ubican estas corporalidades, haciendo de la ironía algo inteligible y menos divertido? Un conocido dato biográfico de Lyra permite acercarse al problema; su condición de hija ilegítima era considerada, según el psicólogo e historiador Alfonso González, como ciudadanía de segunda clase desde el Código Civil de 1886 (González, 1997, 186-188). El reciente estudio biográfico de Annie Lemistre Pujol ha propuesto una hipótesis valiosa, pero aún sin comprobar, sobre ese estigma de la escritora como causa de su proyección heroica en la vida (Lemistre, 2011). El dato sirve para precisar el problema abordado en este artículo: ¿cómo un aspecto biológico forma parte de la vivencia social y literaria femenina, de las relaciones de género y del gobernar? La respuesta no se agota en la vivencia del estigma; preguntar por lo biológico para comprender el lugar de los cuerpos en una escritura, refiere a un proceso histórico más amplio desde el cual se estudia aquí a Carmen Lyra: la biopolítica.

A continuación, se establece ese vínculo entre la escritora y el biopoder determinando, primero, la relación de la institución literaria con la biopolítica, y las formas comunes en que construyen una mirada jerárquica sobre los cuerpos; seguidamente, se contrasta esa mirada jerárquica con la narrativa de Lyra en las décadas de 1910 y 1920, donde podrá apreciarse una propuesta estética sobre los cuerpos vulnerables que la distingue de la "generación del Repertorio" (Quesada, 1996) donde, de manera común, la ha entendido la historia literaria²; finalmente, se observa que la producción intelectual de Lyra no era solo crítica del biopoder, sino que participó también de este, desde su labor magisterial y su militancia comunista, de forma muy particular: creando un culto heroico de ciertos médicos. Para esto, y aquí se plantea una de las hipótesis principales del trabajo, ella trasladó las figuras fantásticas de su mundo literario a los discursos del biopoder; héroes y monstruos escaparon de las páginas literarias hacia el texto biopolítico debido al continuo intercambio de lenguaje entre la literatura, la ciencia y el poder (Arias, 2012-2013; Sarasin, 2003-2007). Demostrar esta traslación que construye la metáfora biopolítica, así como develar la mirada biopolítica jerárquica y la estética de la vulnerabilidad que la preceden, implica un análisis de la obra de la escritora, y de algunas de sus entrevistas publicadas en el periódico comunista Trabajo; esta documentación es contrastada con la narrativa médica y literaria contenida en folletos de higiene, revistas médicas y de literatura.

2 A grandes rasgos, la primera generación literaria denominada "generación del Olimpo", se distingue por una obra costumbrista y plena de anécdotas con valores cuya tradición puede verse afectada por la vida moderna, aunque conciliando la tradición con la ideología del progreso y el liberalismo; sus cultores, además, están ligados a las instituciones del Estado; mientras que la siguiente generación, la "del Repertorio" hace crítica de esa tradición nacional de la oligarquía, denuncia problemas sociales, incluye a grupos de sectores populares y se vincula a proyectos socialistas, anarquistas, teosóficos, entre otros (Quesada, 2002, 15-117). 


\section{Biopolítica y literatura: la epistemología del asco}

Desde los estudios de Michel Foucault, la biopolítica se ha convertido en un concepto tratado desde varias disciplinas, entre ellas la historia. Este concepto se refiere a una racionalidad gubernamental a partir de la cual la vida, lo biológico, se convierte en un dato por gobernar, por lo cual se hacen cálculos, proyecciones e intervenciones sobre las poblaciones, los cuerpos y sus espacios; es entre los siglos XVIII y XIX que los Estados occidentales pasan de un gobierno soberano que hace morir y deja vivir, al biopoder que hace vivir y deja morir (Foucault, 2001a; 2006; 2008). La producción historiográfica sobre lo biopolítico en América Latina aborda temas de medicina social, higienismo, eugenesia o racismo, de tal modo que los estudios biopolíticos confluyen con trabajos en torno a la política social del liberalismo, el control social y la salud pública, pero dando preeminencia a la historicidad del cuerpo y ofreciendo una narrativa no lineal ni ascendente de las ciencias (Pedraza, 2004; Huertas, 2009).

En unos y otros enfoques, las mujeres aparecen como parte de las políticas de asistencia social dirigidas por la institucionalidad eclesiástica, la filantropía liberal y un temprano Estado social, utilizando esa proyección pública y política para trascender el estrecho margen del mundo doméstico legado por el siglo XIX (Eraso, 2009). Es también el caso de Costa Rica, del cual se advierten dos procesos que ayudan a problematizar la dimensión femenina de la biopolítica. Primero, la intervención higienista para transformar y sanear la ciudad capital, proveerla de agua potable y de vías de circulación (Quesada, 2007, 103-148), para esto fue fundamental la profesionalización de la medicina, el paso gradual de una teoría totalizadora de la enfermedad a la bacteriología (Palmer, 2003, 155-182) y las campañas contra la anquilostomiasis dirigidas por el Estado entre 1907-1914, a las cuales se sumó la Fundación Rockefeller entre 1915-1921 y la labor de las educadoras en el magisterio (Palmer, 1999; Palmer, 2003, 104-182). Segundo, la determinación de una "miseria fisiológica" que afectaba las cifras de población (Arias, 2013, 63-107), detrás de estas había un saber estadístico que diagnosticó el problema de la mortalidad infantil y reclamó constantemente a la beneficencia y el saber médico su remedio; el Anuario Estadístico de 1885, publicado por la Sección de Estadística del Ministerio de Fomento, señalaba en tal sentido que:

[Es] palpable en Costa Rica la gran mortalidad en la infancia [...]. Ojalá que nuestros cuadros, y nuestros cálculos puedan servir también para que la ciencia y la filantropía deduzcan favorables consecuencias, para el aumento de la población de Costa-Rica, salvando de la muerte prematura a millares de seres destinados probablemente a vivir largos años (Oficial, 1885, 54-55).

De hecho, el discurso de la auto-inmigración que el historiador Steven Palmer ha ubicado en el gobierno de Cleto González Víquez entre 1906-1910, consistente en la prioridad de fortalecer la salud y la higiene para aumentar 
la población, en vez de estimular la inmigración (Palmer, 1995, 75-85), tenía origen en las ideas de médicos higienistas del cambio de siglo que respondieron a la demanda estadística de curar la mortalidad infantil (Arias, 2013, 93). La investigación del historiador Luis Osvaldo Barrantes et al. sugiere una temprana respuesta al problema de la mortalidad y abandono infantiles a partir de las instituciones de beneficencia del modelo de higiene social del Estado y del modelo moralizador de la Iglesia Católica (Barrantes, Fernández, Fernández, Herrera, Solano, Solano, 1995, 65-155). Fueron considerables las transformaciones institucionales promovidas por ese reclamo estadístico; autoras como Ana María Botey, Ana Paulina Malavassi y Eugenia Rodríguez han recurrido al término de maternidad científica para conceptualizar esa transformación institucional que llevó a la creación de la Escuela de Obstetricia en 1900 y de la Maternidad Carit en 1903 (Malavassi, 2000; Barrantes et al, 1995), de programas sociales como La Gota de Leche en 1913 (Botey, 2008) -iniciativas fundamentales para la posterior creación del Patronato Nacional de la Infancia en 1930-, y a la oficialización del día de la madre en 1932 gracias a las celebraciones magisteriales (Rodríguez, 1998).

Una aproximación conceptual biopolítica a estos procesos revela que intervenir a la población y su espacio implicó un poder directo sobre los cuerpos, sujetos a controles sanitarios y minuciosos regímenes de cuido, y que esa intervención fue notable en los cuerpos de mujeres y niños. El análisis cualitativo de libros y folletos higienistas revela una mirada médica masculina disciplinante de aquellas anatomías fallidas; una de las principales respuestas del modelo higienista al problema de la mortalidad infantil fue la pedagogía de la lactancia, en la cual incursionó el conocimiento de la incipiente bacteriología y se creó una especie de mandato cívico que era, asimismo, físico: se trataba de implantar las ideas de que la vida del niño comenzaba con la disciplina del cuerpo de la mujer, y de que el cuerpo del hijo era una prolongación del cuerpo de la madre (Arias, 2013, 90-105; de Céspedes, 1900a; Pupo, 1913), lo cual obligaba a un régimen de cuidados en torno a hábitos, costumbres, alimentación, vestido, educación física y moral (C.B., 1898, 106-108); ese gobierno de la anatomía alcanzaba y disciplinaba también al cuerpo infantil y al cuerpo de las nodrizas o madres lactantes sustitutas. De ellas, el doctor Benjamín de Céspedes describía en 1900 una serie de controles que pretendía una corporalidad tan idónea como imposible:

La inspección del cuerpo debe ser minuciosa: observar si tiene placas de alopecia, costras en el cuero cabelludo. Si los ganglios del cuello presentan reliquias de escrófula o sífilis, si el semblante es clorótico o anémico, si la caries dentaria está muy extendida (este dato no tiene mucha importancia en la mujer costarricense por estar muy generalizada la caries), si hay secreción fétida de la nariz, mal olor, o placas mucosas en la boca. Al médico tócale apreciar estas manifestaciones y desechar toda nodriza que presente algunos de estos signos. La constitución de la nodriza debe ser sana, aunque no sea vigorosa; su aspecto no será repulsivo. No se debe confiar mucho en los 
pechos voluminosos, porque muchas veces no son más que paquetes de tejido adiposo; hay que notar por la presión el desarrollo nudoso de la glándula, preferir los senos piriformes y cuya piel esté veteada con gran cantidad de venas, a los muy globulosos. El pezón debe ser prominente, ni muy largo ni muy corto, sin fisuras, escamas ni cicatrices. Se auscultarán minuciosamente los pulmones y el corazón. Debe ordenarse a la mujer que se ordeñe, entonces la leche saldrá por los agujeritos del pezón en forma de chorrito y en cantidad apreciable. No es conveniente admitir nodrizas embarazadas o que tengan menstruación. Es prudente registrarles las partes genitales por si padecen de alguna afección venérea (de Céspedes, 1900a, 54-55).

Como puede notarse, los médicos higienistas crearon no solo mandatos cívicos y físicos, sino también estéticos. En revistas como la Gaceta Médica y la Revista Médica, los autores discutieron sobre las implicaciones físicas y legales de la deformación facial ocasionada; para ello recurrieron a la codificación internacional con la cual comparaban y valoraban los códigos y legislaciones del país. Lo importante de esto es advertir que, cada vez que trazaron esas definiciones, emitieron apreciaciones personales sobre lo bello, caracterizando el cuerpo femenino según los suspiros de una profesión eminentemente masculina:

Conforme al Código austriaco, creemos que debiera apreciarse con mayor severidad las deformidades en el sexo femenino; porque si una cicatriz visible en la cara de un hombre no es deformidad notable, en cambio en una doncella, altera los rasgos de su fisionomía hasta el punto de comprometer ventajosos atractivos de su sexo (de Céspedes, 1900b, 121-126).

Nuestra jurisprudencia [...] poca luz nos proporciona sobre este tópico [de la delimitación del rostro]. [En] Medicatura forense [...] debe comprenderse entre la línea frontal superior y el borde inferior de la mandíbula, inclusive los pabellones auriculares. Por nuestra parte no participamos de esta delimitación porque la estimamos sumamente reducida [...]. No sólo opinamos como Jofré y Alimena que comprenden el cuello en la mujer, sino que lo extendemos al hombre; además, el descote femenino debería ser incluido: su visibilidad como complemento de belleza fundamenta nuestro modo de pensar (Zeledón, 1935, 284-293).

En un estudio reciente donde se analiza la mirada médica sobre los cuerpos a partir de las revistas médicas desde fines del siglo XIX hasta la primera mitad del siglo XX (Arias, 2013, 109-174), se ha determinado que las imágenes y narrativas corporales difundidas tendieron a crear una jerarquía estética y de clase que iba del cuerpo saludable y ejemplar del médico descrito de forma épica, descendiendo progresivamente hacia los cuerpos enfermos y deformes narrados desde el asco y la repugnancia, hasta el cuerpo monstruoso contado como figura de horror. La predominante narrativa médica del asco funcionaba como sanción moral sobre los cuerpos de los pacientes, prácticamente de origen popular en su totalidad; en cierta ocasión, un médico contaba haber recibido a un paciente que mostraba "tener poco cuidado en su aseo personal", por lo cual lo intervino quirúrgicamente "habiéndosele ordenado antes un baño y puéstose en condiciones perfectamente higiénicas" (Zumbado, 1896, 
147-148). El caso de una "deformidad horrible" en el rostro llevó a un médico a crear una prótesis facial que permitió a la paciente:

hablar y deglutir con comodidad y haciéndole desaparecer el aspecto desagradable y repugnante de antes [...]. [Una prótesis que] devuelve a un pobre enfermo los medios de hablar, comer y estar tranquilo entre sus semejantes, sin el temor de inspirar repugnancia, haciéndole compatible su vida social (Meza, 1902, 52-53).

¿Qué lugar ocupa la literatura en esa constitución del biopoder? De múltiples maneras, la literatura desde principios de siglo XX es otro más de los saberes que, junto con la estadística y la medicina, constituye el biopoder. En primer lugar, proyectos ideológicos tan disímiles como el del Ateneo de Costa Rica, creado en 1907 como una institución científico-literaria para estimular la cultura intelectual nacional, o el anarquismo con sus organizaciones, publicaciones y proyectos de pedagogía obrera, coincidieron en la popularización de la ciencia y de los distintos saberes desarrollados en torno al gobierno de la vida, las poblaciones y los cuerpos: ese culto redentor de la ciencia les llevó a difundir en sus revistas artículos e imágenes sobre enfermedades, microbios, alcoholismo, higiene y cuidados del cuerpo (Arias, 2013, 178-188). A pesar del elitismo del Ateneo y sus revistas Anales del Ateneo y Athenea, y del obrerismo de grupos anarquistas como el Centro de Estudios Germinal (1912) y la publicación Renovación (1911-1914), los organismos compartieron nombres de miembros y un culto a la ciencia que puede resumirse en la publicación repetida del poema Mi refugio, del arqueólogo y educador Anastasio Alfaro:

\begin{tabular}{|l|l|}
\hline \multicolumn{2}{|c|}{ Cuadro 1. Poema Mi refugio } \\
\hline $\begin{array}{l}\text { "Cada vez que procuro hacer sonetos, } \\
\text { difícilmente encuentro consonantes: } \\
\text { me resultan los versos asonantes, }\end{array}$ & $\begin{array}{l}\text { La rima dejo con dolor profundo, } \\
\text { y en el regazo de mi dulce amiga } \\
\text { olvido el desaliento y la fatiga. }\end{array}$ \\
$\begin{array}{l}\text { lo mismo al comenzar que en los } \\
\text { tercetos. }\end{array}$ & $\begin{array}{l}\text { Es la Ciencia, que puede en un segundo } \\
\text { revelar, si le place, al que investiga, } \\
\text { Al final, me perecen ya discretos, } \\
\text { y en cuartillas los pongo muy } \\
\text { campantes; } \\
\text { pero luego, los hallo discordantes, } \\
\text { largos, cortos, insípidos, escuetos. }\end{array}$ \\
\hline \begin{tabular}{l} 
Fuente: Renovación (2), 30 de enero, 1911, 26; Athenea (1), año 10, 15 de setiembre, 1917, 30. \\
\hline
\end{tabular}
\end{tabular}

En segundo lugar, las obras literarias en cuentos y novelas, no solo de la llamada "generación del Olimpo" de intelectuales decimonónicos, sino también 
de la denominada "generación del Repertorio" al comenzar el siglo XX, abordaron temáticas médicas como enfermedades (D’Alolio, 2004-2005), y ciertas obras constituyeron una forma de diagnóstico sobre los padecimientos de la sociedad, como lo fuera la novela de Joaquín García Monge, Hijas del campo (1900); considerada por el crítico literario Juan Durán Luzio como intento de hacer de la literatura una ciencia experimental siguiendo el modelo de Emile Zola (Durán, 1982), la novela aborda moralmente el tema de la prostitución usando un lente biopolítico, el del control social y la moral del Estado de higiene.

Ambas producciones culturales, las revistas y las obras de ficción, hicieron de la institución literaria un saber constitutivo del biopoder, con la capacidad de emitir discursos y ejercer autoridad de hablar sobre todo aquello por intervenir y gobernar; pese a las diferencias trazadas entre generaciones de escritores, unos y otros coincidieron en construir una epistemología del asco, es decir, un saber biopolítico de los cuerpos no exento de prejuicios frente a la anatomía sucia y enferma de la pobreza. La literatura compartió su lugar de poder al lado de la medicina, narrativas que trataron con repugnancia su encuentro con ese pobre por curar, limpiar y civilizar. La revista Vida y Verdad, editada en 1904 por Joaquín García Monge y Roberto Brenes Mesén, publicó relatos donde se decía que en las viviendas de los campesinos "reina el desaseo más espantoso, hijo de la ignorancia" (Rutenio, 2008a, 232-255) están "saturados de sudor" e "impregnados de impurezas" con "olores repugnantes" (Brescia, 2008, 308-309). El encuentro ficcional entre un mendigo y un médico repitió esa estética:

Con el ademán ceremonioso y un tanto satisfecho de quien se dispone a exhibir lo que constituye un timbre de honor o de orgullo mostró al médico una llaga inmunda que llevaba en una de las piernas, a modo de esas condecoraciones que brotan a millares de los organismos sociales en putrefacción y que la triste soberbia humana compra para ornar el pecho de los hombres eminentes./ Al ver el médico la llaga, sintió todos los bríos de su amor a la ciencia y de su entusiasmo por el bien; se acercó, metió en ella sus dedos y después de examinarla un rato, prometió al mendigo curarlo en breve plazo (Rutenio, 2008b, 192-195).

Compuesto el biopoder por distintos saberes, la literatura era uno de ellos, y compartía con el de la medicina y las campañas de higiene una forma de mirar y narrar los cuerpos: desde una jerarquía estética y clasista que dejaba intacto el lugar de poder de esos saberes y no se internaba en los espacios de su institucionalidad, como esta sí lo hacía en las viviendas de las poblaciones. ¿Qué posicionamiento estético produce la escritura biopolítica de Carmen Lyra?

3 La compaginación de la revista Vida y Verdad pertenece a la edición realizada por Fernando Herrera en García Monge, Joaquín; y Brenes Mesén, Roberto. (Eds.). (2008). Vida y Verdad. San José: Editorial de la Universidad Estatal a Distancia. 


\section{La estética de los cuerpos vulnerables}

A Carmen Lyra se le suele ubicar dentro de la "generación del Repertorio", pero posiblemente sean solo algunos trazos los que la unen a ella. Lyra militó en el temprano anarquismo del siglo XX, pero a diferencia de sus colegas hombres, no vio reducido su radicalismo político al ingresar al magisterio (Molina, 2010); más aún, desde este participó en la politización de las mujeres que contribuyó a derrocar la dictadura de los Tinoco en 1919. En el talante irónico de la escritora, las investiduras literarias del Ateneo, promotor de las actividades cívicas y culturales de la dictadura, tenían poca importancia (Arias, 2013, 298299). Su creación literaria en la década de 1910 marca una distancia considerable respecto al posicionamiento estético de los cuerpos en su generación; muy lejos de la narrativa del asco, Lyra abordó temáticas biopolíticas como la enfermedad, el alcoholismo, la invalidez, la prostitución, el abandono y la mortalidad infantiles desde sus experiencias corporales y con una sensibilidad poco común. Relatos como "Carne de miseria" (1911), "Higiene social" (1912) y "Vidas estériles" (1912), publicados en la revista anarquista Renovación, incluían padecimientos que siempre fueron narrados desde su vivencia corporal:

Ah! Sí, la pobre figura flacucha y triste! Aquella cabeza que se abría como una flor de miseria entre las encantadoras cabecitas rientes de sus compañeras, estaba ante mí, con sus cabellos lacios enmarcando el rostro amarillento y arrugado como el de una viejecilla; la boca entrecerrada; los ojazos hundidos, mirando con su mirada apagada, cual dos llamas que se concluyen; la boca entreabierta, de labios exangües, enseñando los dientes amarillentos, largos, y las encías pálidas (Lyra, 1977, 46).

Era triste aquel rostro. Lo tengo ante mí: pálido, alargado y enjuto, con una palidez de cera vieja, pecoso, la nariz grande, acaballada, que hacía casi ridícula la cara enflaquecida, y los ojos oscuros abriéndose bajo la frente pequeña, tenían una mirada de perro manso (Lyra, 1977, 80).

Varios testimonios sugieren que ella consultaba las revistas médicas y sus historiales sobre los cuerpos enfermos y deformes; incluso, reprodujo en algunos de sus cuentos el lenguaje y el conocimiento médicos, pero no sus prejuicios. Donde un doctor se tapaba la nariz, ella escribía con empatía hacia la vulnerabilidad, revirtiendo la jerarquía de clase de la institucionalidad hospitalaria (Foucault, 2001b; Palmer, 2003, 81-85; Arias, 2013, 114-115). Su literatura hizo el ejercicio, muy poco frecuente para entonces como muestra la historiadora lleana D'Alolio (2004-2005), de ingresar al espacio institucional biopolítico y nombrar sus arbitrariedades e historias de sufrimiento; ello la distanciaba de otros literatos, pero también de una extendida práctica periodística que solía narrar el espacio biopolítico como una arquitectura insufrible (Arias, 2013, 116-120); es decir, una narrativa deslumbrada por los jardines y pabellones de hospitales, pero desatenta de las personas y dolencias que los habitaban. Posiblemente ella usó las revistas médicas con sus historiales como material literario; un relato de 1917, “¿Para qué?”, reprodujo las mismas metáforas 
vegetales que algunos médicos emplearon para describir las deformaciones provocadas por enfermedades, pero ello no significó narrar el cuerpo con asquerosidad, ni tampoco obviar el sufrimiento ocurrido al interior del espacio hospitalario al contemplar sus jardines:

¿Albina no había visto aún su tumor? Los médicos lo guardaron en alcohol. Era del tamaño de una toronja. Juana e Inés sí lo conocían. Inés lo vio dos veces. Y miró a Juana y a Inés complacida, deteniendo sus miradas en Inés como si el haberlo tenido esta mujer ante los ojos más veces fuera una gran prueba de cariño hacia ella. Luego añadió con una alegría casi infantil que ella lo había visto ya cinco veces./ Escuchándola, Albina sentíase cada vez más desolada [... . Era una mañana radiante, con un cielo muy azul. Los jardines del hospital estaban llenos de flores y sobre ellos, como chispas vibrantes, zumbaban enjambres de abejas amarillas. Los corredores estaban poblados de enfermos, cuya miseria física parecía más triste en aquella brillante mañana (Lyra, 1977, 160)4.

Si consideramos los análisis de la teórica feminista Rosemarie Garland Thomson, quien distingue cuatro formas de mirar la discapacidad (maravillosa, sentimental, exótica, realista) (Garland Thomson, 1997; Garland-Thomson, 2002, 56-75), y quien, junto con la especialista en estudios sobre la discapacidad Joanna C. Rankin (Rankin, 2009), observa que la discapacidad en la literatura ocupa generalmente un lugar sin agencia ni subjetividad, tendiente a estereotipos de lástima, maldad o patetismo, encontramos entonces que la mirada de Lyra sobre el cuerpo inválido es realista y emocional; más que sentimentalista, tiende a metaforizar emociones a través de los cuerpos, y su metaforización reivindica la vulnerabilidad (Ziemer, 2008, 97-107)5. En su novela En una silla de ruedas, publicada en 1919 y reeditada a mitad de los años cuarenta, el abandono materno es una mutilación, los huérfanos traen al mundo hijos ilegítimos que son amados, los inválidos son amigos de alcohólicos, y entre todos cuidan de sí (Arias, 2013, 303-308); lejos de idealizar el escenario de lavulnerabilidad social, la obra posee un destacado valor biopolítico en torno a los cuerpos vulnerables por cuanto produce un discurso sobre la discapacidad cuando esta no existe como concepto ni identidad política (Arias, 2013, 288)6; en la novela, las metáforas corporales llenan ese vacío conceptual,

$4 \quad$ El tumor del "tamaño de una toronja” fue la metáfora empleada por el médico Luis Jiménez en 1915 para disertar sobre un caso de quiste de ovario en los Anales del Hospital de San José (Jiménez y Facio, 1915, 47-54).

5 Siguiendo a Ziemer (2008), la estética de la vulnerabilidad refiere al conocimiento de la peligrosidad del cuerpo y de la vida, mostrando que la exclusión y la agresión de los otros son consecuencia del miedo a la vulnerabilidad, evitando los anclados dualismos de lo normal-anormal, lo saludableenfermo, lo bello-feo. Es una categoría estética, una figura reflexiva que no se basa en dicotomías; promueve una ética que hace mirar no la otredad en el otro, sino la otredad en mí.

6 La novela constituye una trama excepcional de la vulnerabilidad y la discapacidad, en tanto reivindica un hogar dirigido por la invalidez e integrado por la orfandad, la ilegitimidad, el alcoholismo y el abandono infantil; la investigación de Mariana Campos indica que en el censo de 1927, solo un 0,5\% de los 94793 hogares registrados tenía un jefe con discapacidad (Campos, 2013), de allí la excepcionalidad de la trama literaria. La historiadora Patricia Alvarenga ofrece otra aproximación a la novela: 
y se denuncia la mirada de asombro que hace de la discapacidad un fenómeno (freak) de entretenimiento y lucro:

Desde una semana antes de llevarse a cabo la primera audición, los diarios movieron en sus columnas los incensarios, ante el célebre organista inglés y el violinista nacional. Todo lo que se contaba de éste, rodeaba su nombre de leyenda. Y quizá fue más la curiosidad de ver en el escenario a un violinista paralítico, y no el deseo de oír buena música, a la que nuestro público no es aficionado, lo que llenó el Teatro [...]. La novelería ha dejado por fin tranquilo a Sergio: se encontraba incómodo entre tantas gentes que no hablaban nada a su corazón, y a quienes veía acudir a contemplarlo como un fenómeno raro. La paja ha sido aventada y Sergio ha descubierto que bajo tanta balumba solo había un que otro grano bueno (Lyra, 1972a, 165-166).

Varios de sus cuentos, al iniciar la década de 1920, tendieron a metaforizar con cuerpos, aspectos sensibles del curso biopolítico del país. Piezas como "Ramona, la mujer de la brasa" (1923) y "El marimbero" (1924) metaforizan un agotamiento del instinto maternal y sus cuerpos justo cuando el feminismo triunfante contra la dictadura tinoquista reivindica la maternidad como una política pública; en el primer cuento, el desgaste corporal de una mujer, luego de diez partos, se traduce en un amor deteriorado hacia sus hijos, quienes le devuelven odio (Lyra, 1972b, 67-73); en el segundo cuento, un marimbero cuya deformidad facial encuentra su único consuelo en la marimba, es reclutado para defender la dictadura tinoquista, regresando posteriormente al hogar materno con sus brazos mutilados, solo para escuchar de su madre: "Es verdad que te quedaste sin brazos [...]. ¡Y ora quién te va a mantener!" (Lyra, 1977, 309-314).

Esas historias de mutilación del amor materno intensifican su contenido biopolítico en el relato “El Barrio Cothnejo-Fishy" (1923), el cual plantea una crítica a la segregación urbana vivida en la ciudad capital, denunciada continuamente en la década de 1920 (Elizondo, 1998), y a las tendencias aristocráticas de los habitantes acaudalados del Barrio Amón; el recurso de Lyra es hacer una anatomía de la desigualdad social, es decir, observar las diferencias de clase a través de su vivencia corporal, descifrar cómo se vive corporalmente una clase social: Ios cuerpos desnutridos de la pobreza y los tejidos grasosos de la riqueza. Su crítica anuncia el comunismo casi una década antes de su formación en el país, denuncia el elitismo feminista liberal y hace aparecer el cuerpo del monstruo, no como en las revistas médicas, resultado de la suciedad incivil popular (Arias, 2013, 161-172), sino como engendro de la moral burguesa decadente e infectada:

La hostería era una casa de apariencia inofensiva [...]. Rondaban por allí mujeres quemadas por el vicio, vestidas de trajes de un brillo de mal gusto, la

como anticipo de la crítica comunista a la moral burguesa y como expresión de formas alternativas del poder femenino (Alvarenga, 2012, 121-124, 221-224). 
cara pintarrajeada. La música de un Jazz pirueteaba desganada por aquellos pasillos oscuros y ponía en movimiento de una libidinosidad grotesca a unas parejas. A ese lugar fue a parar la pandilla formada por jóvenes de la crema y nata de nuestra sociedad [...]. Allí siguieron bebiendo y prostituyéndose el cuerpo y el alma. Allí cogió Lucho aquella sífiles [sic] que treinta años más tarde le produjo la parálisis general que se lo llevó hecho un idiota a la tumba, a pesar de sus maneras que nunca desentonaron en un salón o en una mesa donde se consagra a una persona como cosa distinguida, o como cosa vulgar, según se conduzca a la hora de comer por ejemplo los espárragos. Así se preparó aquel señoritingo de familia de rango, para celebrar su matrimonio. La sífilis que adquirió esa noche fue la causa de los abortos de Cristinita, del niño que dichosamente naciera muerto y que aunque era de tiempo, tenía los ojos, las manos y los pies a medio desarrollar. Fue una sífilis que todavía se presentó en los bisnietos de Lucho y Cristinita y que se manifestó en ojos que eran como fuentes de pus, en sorderas, en narices mal olientes, en paladares hendidos y labios leporinos, en raquitismos, obesidad, gigantismo, corazones enfermos, en abortos de carne macerada, y en todas esas monstruosidades, locuras y deformaciones que hielan el pensamiento cuando se medita en ellos (Lyra, 1977, 267-268).

¿Qué procesos históricos conformaron el esqueleto de esas metáforas corporales? Lyra había militado en el anarquismo e incluso había dirigido la revista Renovación en su último año de circulación en 1914, ello la acercaba a un permanente interés por la ciencia y sus expresiones biopolíticas. Después, tomó parte de un evento político que invirtió, de forma radical, un orden social y de género aferrado al destino biológico: las mujeres y su politización frente a la dictadura, cuyo legado dejara una estela de represión política y física con secuelas de discapacidad y trauma en los opositores, tanto hombres como mujeres (Bonilla, 2008). Ese pasaje político, y su prestigiosa trayectoria de escritora y educadora, le valieron una beca para estudios pedagógicos en el exterior, lo que le permitió conocer la Europa desgarrada por la Gran Guerra (1914-1918), sus miles de cuerpos mutilados e inválidos, y los efectos estéticos que ello tuvo en la literatura y el arte (Arias, 2013, 314-315). En 1935 recordaba de aquella época: "Después de la guerra yo había visto en Europa troncos de soldados con el pecho constelado de cruces y medallas ganadas en las batallas que los habían dejado sin brazos ni piernas, arrastrándose por las calles y pidiendo limosna" (Lyra, 1935, 4).

Lyra contribuyó así a que un país como Costa Rica formara parte de un proceso global de transformación en la sensibilidad hacia el cuerpo inválido, para lo cual fue determinante la experiencia de dos guerras mundiales, sus millones de muertos, y la cultura de rehabilitación de sus heridos (Courtine, 2006). 


\section{Héroes y monstruos, fugitivos literarios (las metáforas del biopoder)}

La escritura de Lyra no fue una permanente inversión de la mirada jerárquica del biopoder; la relación de la literatura con la biopolítica es compleja. Desde su experiencia magisterial en los años veinte, pero también desde la militancia del comunismo en los treinta, Lyra fue una exponente excepcional y ambivalente del gobierno biopolítico de los cuerpos. La complejidad de ese vínculo se denota en el testimonio de un médico en 1934, quien publicó en la Revista Médica la crónica de un método terapéutico en el cual las larvas de una especie de mosca se nutrían de las partes "mortificadas y purulentas de las heridas donde se las coloca, respetando los tejidos sanos". Para su crónica, el autor tuvo dos referencias; primero, el reconocido parasitólogo, doctor Clodomiro Picado; segundo, un "trabajo científico literario" publicado por Lyra en la revista Repertorio Americano, gracias al cual pudo conocer en detalle las larvas; al final, el doctor admitía "que debido a nuestra indolencia, son los literatos a veces quienes nos traen las actualidades científicas y naturalmente vestidas con ropajes literarios que llegan hasta las fantasías más imposibles" (Zeledón, 1934, 104-106).

Ciertamente, el ropaje literario del saber biopolítico tuvo fantasías insospechadas; el constante intercambio de lenguaje entre la literatura, la ciencia y la política condujo a que héroes y monstruos, personajes del mundo literario de Lyra, escaparan de las páginas de sus cuentos, haciendo que la literatura proveyera al biopoder de un tiempo heroico al cual rendir culto. Este culto no fue un fenómeno del todo novedoso, la misma corporación médica tendía a presentarse socialmente desde narrativas e imágenes épicas, incluso a la hora de contar la historia de la higiene o contrastar en revistas sus cuerpos con los de pacientes enfermos (Arias, 2013, 150-161; Latour, 2007, 111-175); de igual forma, los intelectuales y sus revistas, a partir de la popularización y difusión de la ciencia, tendieron a reforzar la imagen mesiánica de los médicos (Arias, 2013, 198-207). Una de los principales soportes que tuvieron las campañas higienistas a comienzos de siglo fue la infraestructura básica que legara la reforma educativa de 1886, junto con la creación del Departamento de Sanidad Escolar en 1914 (Palmer, 1999, 104-105); fue este el contexto en que Lyra, quizá por primera vez, contribuyó a crear ese culto heroico del biopoder, empleando como metáforas las figuras del héroe y del monstruo, fugitivos de los mundos literarios de la escritora. En 1924, en un texto escrito para ser leído en el espacio escolar por su lenguaje pedagógico y a la vez fantástico, reverenciaba la figura del recién fallecido doctor Carlos Durán, médico organizador de las campañas higienistas contra el parásito de la anquilostomiasis a comienzos del siglo XX. El fascinante texto titulado "Un gran civilizador costarricense" decía:

¡Qué bueno hubiera sido que a los niños de esa época les hubiesen contado en la escuela que el doctor Durán era un empresario a la manera de 
Hércules, el de la mitología griega, y que estaba metido en trabajos que han ennoblecido la vida del pueblo de Costa Rica! A los niños les hubiera impresionado mucho, por ejemplo, que al enseñarles cosas de nuestra historia, les hubieran narrado aquella hazaña del doctor Durán, que consistía en haber encontrado al monstruo que debilitaba y mataba a nuestro pueblo. El monstruo a que me refiero es horrible, y todavía se le encuentra en muchos lugares de Costa Rica; pero ya no vive tan seguro como antes de que lo encontrara en su escondite el doctor Durán. Figuráos niños, que es un monstruo con una bocaza con ganchos como las brujas malas, que echa un veneno que deja a la gente sin ganas de mover un dedo [...] hablemos primero del caballero que descubrió al monstruo en su escondrijo, y se puso a combatirlo con el empeño y la tenacidad que ponían los caballeros de las leyendas, que se iban por esas tierras de Dios a acabar con el dragón que se comía los habitantes de una población (Lyra, 1972b, 121-135).

La construcción de un culto heroico del biopoder no fue un evento limitado al quehacer magisterial de Lyra; durante su militancia comunista en los años treinta procedió de manera similar al rememorar al doctor Ricardo Moreno Cañas, asesinado en 1938 por un paciente que resentía no haber sido curado de su deformidad en un brazo (García, 2012); Lyra contribuyó al proceso de santificación popular que experimentó el recuerdo del médico (Low, 1988, 49-66), reconocido por extraordinarias operaciones ${ }^{7}$ que lograron enderezar piernas gravemente anquilosadas:

Con sus manos extraordinarias [...] el Dr. Moreno se dispone a dejar sana la pierna deforme [...] es la vida de un muchacho; es la vida de un trabajador [...]. El pasaje del Evangelio de San Mateo, cuando Jesús invita al paralítico a levantarse, tomar la cama y volver a su casa, se nos viene a la memoria (Lyra, 1938, 1, 4).

Moreno Cañas fue el primer especialista en ortopedia del país, formado en Europa y cirujano voluntario en el Hospital de Cirugía de Guerra en París, en tiempos de la Primera Guerra Mundial, por lo cual fue condecorado. De este modo, Lyra consolidaba una práctica narrativa que hizo saltar del mundo de los cuentos a figuras míticas o fantásticas para darles sentido en los discursos del biopoder; su paso por el comunismo, su influencia en las políticas de higiene y de cuido infantil del partido (Molina, 2000; Botey, 2008-2009), su posterior adopción de una perspectiva moralista en torno a la sexualidad y la prostitución dentro del comunismo (Alvarenga, 2007; 2012, 129-134; FlórezEstrada, 2013), la difusión del maternalismo en la militancia antifascista (Arias, 2008), y los cultos al cuerpo obrero que allí promovió, le llevaron a adoptar la

$7 \quad$ Moreno Cañas había operado igualmente al hermano de Lyra, luego de ser herido de bala durante una manifestación; resulta difícil determinar en qué momento sucede esto, si durante la militancia de fines de los años veinte en la Liga Cívica, como indica Gabriel Quesada, familiar de la escritora (Quesada, 2009), o en un mitin del Partido Comunista en los años treinta, como se señala en Trabajo $(1938$, 3). Este hecho quizá favoreciera una cercanía personal de la escritora con el médico, pese a las diferencias políticas que tuvieron, uno como diputado del Partido Republicano Nacional, y ella como militante comunista (Arias, 2013, 343-344). 
cultura de rehabilitación heredada por la primera posguerra y a difundir el culto al cuerpo hábil en función de una economía política del trabajo vinculada a la intervención biopolítica liberal (Arias, 2013, 336-364).

Es posible que esa adscripción reparara las corporalidades dolidas que siempre poblaron la literatura y sensibilidad de Lyra; luego de su ingreso al comunismo, ella publicó poco, pero existen varios indicios de que su estética de la vulnerabilidad, enderezada ahora por la ortopedia, alcanzó la literatura obrera creada al interior del partido ${ }^{8}$, mientras que algunos de sus pocos relatos en la era de su militancia comunista, como "Bananos y hombres" (1931) o "Los diez viejitos de Pastor" (1936), dramatizaron los mundos del trabajo desde sus dolencias anatómicas, en el segundo relato, los diez dedos de un peón agrícola (Lyra, 1940, 2). Más que un asunto de ironía, esa mirada a los cuerpos vulnerables fue para ella una obsesión, y como tal la definió en una entrevista de 1935 donde rememoraba su paso por la Escuela Maternal a finales de los años veinte:

Luego los pies de estos chiquillos [...]. A mí se me volvieron una obsesión los piececitos de todos aquellos niños: patillas descalzas tan a menudo heridas, que venían renqueando de su casa, envueltas en unos trapos sucios: patillas calzadas de un modo fantástico con unos zapatos nunca nuevos, siempre torcidos, a veces el talón de fuera, las suelas abiertas en muecas como de burla por la miseria, unos deditos medrosos asomando por la despiadada abertura. Los 3 niños de un zapatero andaban descalzos. El padre sabía hacer zapatos, pero su habilidad de nada servía a sus hijos. Yo pensaba en los pies de niños que iban semidescalzos en aquella forma o descalzos del todo [...]. Logré contagiar mi obsesión a don Arturo Urien, el cónsul de la Argentina, el viejo más bueno que en mis días he visto, quien todas las mañanas llegaba a la Escuela Maternal a ver qué podía hacer por los niños. Y don Arturo calzóconsandaliastodasaquellaspatillas desnudas. Ydesdeentonces, mientras permaneció en Costa Rica, don Arturo empleó parte de sus entradas en proteger piecesitos de niños costarricenses. Cuando yo veía a los chiquillos de la Maternal corriendo y brincando al son de la música del piano, me preguntaba adónde llevarían a sus dueños esos pies ahora pequeñitos. Si las cosas seguían como estaban, sería hacia las congojas, hacia el dolor, quizá a la cárcel. Las cárceles están llenas de pies que casi siempre han andado descalzos o mal calzados (Lyra, 1935, 4).

\section{Biopolítica, anatomía y metafórica final}

En su juventud, Carmen Lyra no pudo incorporarse como novicia al Hospital San Juan de Dios debido a su condición de hija ilegítima; ese episodio ha servido para subrayar una constante religiosidad en su escritura y en su

8 Su participación en la formación de una literatura obrera y en la creación del escritor Carlos Luis Fallas sugiere que obras colectivas como Pescadores de atún (Molina, 2012), o Mamita Yunai (1941) de Fallas, plenas de corporalidades obreras dolidas o heridas, fueron una prolongación de esa estética de los cuerpos vulnerables heredada por Lyra (Arias, 2012; 2013; Fallas, 2002). 
pensamiento político (Solís, 2006, 109-110). Si bien la cultura bíblica latente en el lenguaje comunista costarricense hace necesaria una investigación sobre la religiosidad de sus militantes, este artículo prefiere llamar la atención sobre la constante del interés médico y el motivo del cuerpo en la escritora. Aunque probablemente vinculado a la condición biográfica de la ilegitimidad y la femineidad, que fijaban una marca biológica sobre lo social, ese interés médico y anatómico se contiene de múltiples experiencias políticas y culturales que involucran: a) al anarquismo de la década de 1910, su difusión de la ciencia y su atención al cuerpo de la pobreza y del obrero; b) su participación en el derrocamiento de una dictadura con secuelas traumáticas y de discapacidad; c) la presencia en la Europa de la primera posguerra, donde observara los cuerpos heridos y mutilados de excombatientes, y sus efectos en la literatura y el arte; c) la actividad magisterial que en la década de 1920 forma parte de la política social del Estado y su observancia de la niñez, hasta la creación en 1930 del Patronato Nacional de la Infancia (PANI); d) la militancia comunista y su promoción de políticas de higiene y cuido social, así como un nuevo interés por la cultura obrera y sus cuerpos, marcando estos la literatura del partido; y e) una trayectoria narrativa que acude a la literatura médica y hace del cuerpo protagonista y metáfora, estética que incide en la cultura comunista.

El estudio de la biopolítica en la historiografía costarricense es incipiente; no obstante, existe una considerable bibliografía, parte de ella citada a lo largo de este artículo, en torno a la historia social de la medicina, a la política social del liberalismo y a la demografía histórica que permite discernir la aparición y desarrollo de una intervención gubernamental de las poblaciones que apuntaba hacia la prolongación de la vida, la contención de la muerte y el saneamiento del espacio. Un ángulo conceptual biopolítico complementa la comprensión de esa racionalidad gubernamental desde al menos dos criterios; primero, el gobierno de la vida implica un gobierno de los cuerpos, una anatomopolítica que acompaña la biopolítica de las poblaciones y que actúa con intención minuciosa no menos prejuiciosa y no siempre efectiva, sobre el cuerpo individual para hacer manipulable un cuerpo social (Castro, 2011, 15-68; Huertas, 2009); segundo, el biopoder se constituye de saberes, dos de los cuales, la estadística y la medicina, se interpelan y demandan intervenir esa anatomía observable, manipulable y cuantificable.

Se propone en el artículo, siguiendo otros trabajos ya citados (Arias, 2012; Arias, 2013), que la literatura constituye, al lado de la profesionalización médica y las institucionalidades estadística y hospitalaria, una parte del biopoder en virtud de la considerable participación de escritores y revistas en la difusión de la ciencia y, con ella, de los saberes biopolíticos y de los cuerpos. En tanto autoridad que enuncia discursos, construye un régimen de verdad y ejerce con ello un poder (Foucault, 2002), el saber ejercido por la literatura es complejo y ambivalente, y el caso de Carmen Lyra lo demuestra bien. Escritores y escritoras participan en instituciones como el magisterio, que les 
coloca en una posición mediadora del gobernar los cuerpos. Su narrativa, de ficción o en prosa, tematiza cuerpos e instituciones, reproduciendo saberes, lenguajes y prejuicios.

Con Lyra es posible apreciar la complejidad de esa dimensión literaria del biopoder. En primera instancia, ofrece una mirada alterna y empática de los cuerpos, todos aquellos que burlan o resienten los discursos e instituciones biopolíticos; ella ingresa en esos espacios institucionales y advierte sus arbitrariedades. Es común en los estudios del cuerpo y lo monstruoso encontrarse con la afirmación de que el cuerpo, como el monstruo, siempre escapa (Cohen, 1996, 3-25). En tal sentido, la escritora es narradora de esa fuga, pues su empatía y sensibilidad dan espacio al protagonismo y la agencia de la otredad corporal; ello ocurre no solo porque así lo cuentan sus relatos y novelas, sino porque estos sirven como metáforas de una realidad social y política, los cuerpos literarios se recubren de significaciones que posicionan discursos críticos frente al feminismo y la filantropía liberales, la desigualdad social y la arbitrariedad hospitalaria, anunciando conceptos o agendas políticas que aún no forman parte del escenario político: por un instante, la discapacidad; en otro, el comunismo. En un segundo momento, cuando forma parte de la política social del Estado desde el magisterio, y cuando milita dentro de un comunismo atento al saneamiento de la capital, Lyra no aparece como la crítica del biopoder, sino como una de sus cultoras, construyendo un tiempo heroico en el cual ciertas figuras eminentes de la medicina aparecían rememoradas con un lenguaje épico donde las imágenes del mundo literario de la escritora eran resignificadas dentro de los discursos biopolíticos. Esta es una de las principales conclusiones de este artículo; la conjunción de lenguajes entre la literatura, la ciencia y el poder gubernamental provocó traslaciones de imágenes verbales, metáforas que revelaban más de lo que posiblemente sus narradores se propusieran (Sarasin, 2003), evidenciando el lugar constituyente del saber literario dentro del biopoder. Esa condición de la literatura como saber tiene no pocas implicaciones en las formas de considerarla como fuente documental de la historiografía: la literatura no solo responde a una historia literaria, sino también a una historia del poder, a una historia gubernamental.

\section{Referencias}

Alvarenga Venutolo, Patricia. (2007). Sexualidad y participación política femenina en la izquierda costarricense. Inter.c.a.mbio, 4 (5), 231-267.

Alvarenga Venutolo, Patricia. (2012). Identidades en disputa: las reinvenciones del género y de la sexualidad en la Costa Rica de la primera mitad del siglo XX. San José: Editorial de la Universidad de Costa Rica.

Arias Mora, Dennis. (2008). Carmen Lyra: escenarios políticos, culturales y subjetivos en la era antifascista. Revista de Ciencias Sociales, (120), 65-79. 
Arias Mora, Dennis. (2012). El viaje del héroe al espacio monstruoso: metáforas de un saber biopolítico hecho novela. Revista CS, (9), 55-86.

Arias Mora, Dennis. (2013). Criaturas de lo heroico y monstruoso. Metáforas del saber biopolítico y sus cuerpos (Costa Rica, 1900-1946). Tesis doctoral en Historia, Universidad Libre de Berlín, Berlín, Alemania.

Barrantes Barrantes, Luis Osvaldo; Fernández Cartín, Liliana; Fernández Dormond, Nydia; Herrera Blanco, Ricardo; Solano Montenegro, Flor Eugenia; Solano Ramírez, Sonia. (1995). Política social, beneficencia y abandono de niños en Costa Rica (1890-1930). Tesis de Licenciatura en Historia, Universidad de Costa Rica, San José, Costa Rica.

Bonilla Castro, Alejandro. (2008). Movimientos sociales y represión del Estado en la dictadura de Tinoco 1918-1919. Diálogos, (número especial). Recuperado el 18 de febrero del 2014 de http://historia.fcs.ucr.ac.cr/articulos/2008/ especial2008/articulos/06-politica/64.pdf

Botey Sobrado, Ana María. (2008). De la beneficencia a la filantropía "científica": la fundación de La Gota de Leche (1913). Diálogos, (número especial). Recuperado el 18 de febrero del 2014 de http://historia.fcs.ucr.ac.cr/ articulos/2008/especial2008/articulos/05-Economia/58.pdf

Botey Sobrado, Ana María. (2008-2009). Salud, higiene y regidores comunistas, San José (1933). Diálogos, 9 (2). Recuperado el 18 de febrero del 2014 de http://www.redalyc.org/pdf/439/43913132001.pdf

Brescia, Ugo. (1904). Medallas y escapularios. En García Monge, Joaquín; y Brenes Mesén, Roberto. (Eds.) (2008). Vida y Verdad. San José: Editorial de la Universidad Nacional Estatatal a Distancia, 308-309.

C. B. (1898). Programa del concurso médico científico nacional para el año de 1899. Gaceta Médica, (7), 15 de febrero, 106-108.

Campos Vargas, Mariana. (2013). La población con discapacidad en los censos del siglo XX en Costa Rica. Población y Salud en Mesoamérica, 11 (1), 1-43.

Castro, Edgardo. (2011). Lecturas foucaulteanas. Una historia conceptual de la biopolítica. La Plata: Universidad Pedogógica-Editorial Universitaria.

Cohen, Jeffrey Jerome. (1996). Monster Culture (Seven Theses). En Cohen, Jeffrey Jerome. (Ed.). Monster theory. Reading culture. Minneapolis-London: University of Minnesota Press, 3-25.

Courtine, Jean-Jacques. (2006). El cuerpo anormal. Historia y antropología culturales de la deformidad. En Corbin, Alain; Courtine, Jean-Jacques; y Vigarello, Georges. (Eds.). Historia del cuerpo. Volumen 3: El siglo XX. Madrid: Taurus, 201-258. 
De Céspedes, Benjamín. (1900a). Higiene de la infancia en Costa Rica. San José: Tipografía Nacional.

De Céspedes, Benjamín. (1900b). Comentarios médico-legales. Legislación de Costa Rica. Lesiones corporales. Jurisprudencia-Interpretación. Gaceta Médica, (5), 15 de diciembre, 121-126.

D’Alolio, Ileana. (2004-2005). El discurso literario costarricense sobre enfermedad mental y locura femenina (1880-1914). Diálogos, 5 (1-2). Recuperado el 18 de febrero, 2014 de http://www.revistas.ucr.ac.cr/index.php/dialogos/ article/view/6234/5937

Durán Luzio, Juan. (1982). Un caso de relación literaria: Emile Zola y Joaquín García Monge. Revista de Filología y Lingüística, 8 (1-2), 37-43.

Elizondo Calderón, William. (1998). Vivienda y pobreza en la ciudad de San José en la década de 1920. Anuario de Estudios Centroamericanos, 24 (1-2), 47-74.

Eraso, Yolanda. (Ed.). (2009). Mujeres y asistencia social en Latinoamérica, siglos XIX y XX: Argentina, Colombia, México, Perú y Uruguay. Córdoba: Alción.

Ethal, Claudio. (1923). Con Carmen Lira. Bohemia, (29), 10 de junio, 3-4.

Fallas, Carlos Luis. (2002). Mamita Yunai. San José: Editorial Costa Rica.

Flórez-Estrada, Pimentel. (2013). La disputa olvidada. Revista Estudios, 26 (1).

Foucault, Michel. (2001a). Defender la sociedad (Curso en el Collège de France (1975-1976). Buenos Aires: Fondo de Cultura Económica.

Foucault, Michel. (2001b). El nacimiento de la clínica. Una arqueología de la mirada médica. México: Siglo XXI Editores.

Foucault, Michel. (2002). La arqueología del saber. Buenos Aires: Siglo XXI Editores.

Foucault, Michel. (2006). Seguridad, territorio, población: Curso en el Collège de France: 1977-1978. Buenos Aires: Fondo de Cultura Económica.

Foucault, Michel. (2008). El nacimiento de la biopolítica. Curso en el Collège de France 1978-1979. Buenos Aires: Fondo de Cultura Económica.

García Monge, Joaquín y Brenes Mesén, Roberto. (Eds.). (2008). Vida y Verdad. San José: Editorial de la Universidad Nacional Estatatal a Distancia.

García Quesada, George. (2012). La infamia de Beltrán Cortés. Hegemonía, nacionalismo y control social en Costa Rica, 1938-1939. A Contracorriente, 10 (2), 23-57. 
Garland Thomson, Rosemarie. (1997). Extraordinary Bodies. Figuring Physical Disability in American Culture and Literature. New York: Columbia University Press.

Garland-Thomson, Rosemarie. (2002). The Politics of Staring: Visual Rhetorics of Disability in popular Photography. En Snyder, Sharon L.; Brueggemann, Brenda Jo; y Garland-Thomson, Rosemarie. (Eds.). Disability Studies: Enabling the Humanities. New York: Modern Language Association, 56-75.

González Gutiérrez, Luisa. (2006). Cómo conocí a Carmen Lyra. En González Gutiérrez, Luisa. Escritos. Heredia: Editorial de la Universidad Nacional, 116-120.

González Ortega, Alfonso. (1997). Vida cotidiana en la Costa Rica de/ siglo XIX. Un estudio psicogenético. San José: Editorial de la Universidad de Costa Rica.

Goschler, Juliana. (2005). Embodiment and Body Metaphors. metaphorik.de, (09), 33-52. Recuperado el 18 de febrero del 2014 de http://www.metaphorik.de/sites/www.metaphorik.de/files/journal-pdf/09_2005_goschler.pdf

Huertas, Rafael. (2009). Medicina social, control social y políticas del cuerpo. La subjetivación de la norma. En Miranda, Marisa; Girón Sierra, Álvaro (Coords.). Cuerpo, biopolítica y control social. América Latina en los siglos XIX yXX. Buenos Aires: Siglo XXI Editores, 19-41.

Jiménez, Luis P. y Facio, A. A. (1915). Un caso de quiste multilocular del ovario. Anales del Hospital de San José, (1), 15 de setiembre, 47-54.

Latour, Bruno. (2007). Krieg und Frieden. Starke Mikroben-Schwache Hygieniker. En Sarasin, Philipp et al. (Ed.). Bakteriologie und Moderne. Studien zur Biopolitik des Unsichtbaren. 1870-1920. Frankfurt am Main: Suhrkamp, 111-175.

Lemistre Pujol, Annie. (2011). Carmen Lyra. El cuento de su vida. San José: Alma Máter.

Low, Setha M. (1988). Medical doctor, popular saint: The syncretic symbolism of Ricardo Moreno Cañas and José Gregorio Hernández. Journal of Latin American lore, 14 (1), 49-66.

Lyra, Carmen. (1935, 28 de julio). El régimen capitalista es el pasado. Trabajo, 4.

Lyra, Carmen. (1938, 3 de setiembre). De la admirable operación que el Dr. Moreno hizo a un muchacho jornalero ayudado por los doctores Jorge Vega y Fernando Pinto. Trabajo, pp. 1 y 4.

Lyra, Carmen. (1940, 24 de febrero). Los diez viejitos de Pastor. Cuento de Carmen Lyra. Trabajo, p. 2. 
Lyra, Carmen. (1972a). Obras completas de María Isabel Carvajal "Carmen Lyra". Tomo I. San José: Patria Libre.

Lyra, Carmen. (1972b). Ramona, la mujer de la brasa. En González, Luisa; y Sáenz, Carlos Luis. Carmen Lyra. San José: Ministerio de Cultura, Juventud y Deportes, 67-73.

Lyra, Carmen. (1972b). Un gran civilizador costarricense. En González, Luisa; y Sáenz, Carlos Luis. Carmen Lyra. San José: Ministerio de Cultura, Juventud y Deportes, 121-135

Lyra, Carmen. (1977). Carne de miseria. En Lyra, Carmen. Relatos escogidos. San José: Editorial Costa Rica, 45-48.

Lyra, Carmen. (1977). Vidas estériles. En Lyra, Carmen. Relatos escogidos. San José: Editorial Costa Rica, 80-84.

Lyra, Carmen. (1977). ¿Para qué? En Lyra, Carmen. Relatos escogidos. San José: Editorial Costa Rica, 156-160.

Lyra, Carmen. (1977). El Barrio Cothnejo-Fischy. En Lyra, Carmen. Relatos escogidos. San José: Editorial Costa Rica, 259-274.

Lyra, Carmen. (1977). El marimbero. En Lyra, Carmen. Relatos escogidos. San José: Editorial Costa Rica, 309-314.

Malavassi, Ana Paulina. (2000). De parteras a obstétricas: la profesionalización de una práctica tradicional. Costa Rica 1900-1940. Examen preliminar. El Salvador: Ponencia del V Congreso Centroamericano de Historia.

Meza, Rafael. (1902). Variedades. Un caso de prótesis palatino-nasal. Gaceta Médica, (2), noviembre, 52-53.

Molina Jiménez, Iván. (2000). Un pasado comunista por recuperar. Carmen Lyra y Carlos Luis Fallas en la década de 1930. En Lyra, Carmen; y Fallas, Carlos Luis. Ensayos políticos. San José: Editorial Universidad de Costa Rica, 9-66.

Molina Jiménez, Iván. (2010). El discurso de Joaquín García Monge en 1921. En Molina Jiménez, Iván. Moradas y discursos. Cultura y política en la Costa Rica de los siglos XIX y XX. Heredia: Editorial de la Universidad Nacional, 127-153.

Molina, Iván. (Comp.). (2012). Pescadores de atún y otros cuentos proletarios costarricenses. San José: Grupo Nación S.A.

Oficial. (1885). Anuario estadístico de la República de Costa Rica. Año 1885. San José: Imprenta Nacional. 
Palmer, Steven. (1995). Hacia la "auto-inmigración". El nacionalismo oficial en Costa Rica, 1870-1930. En Taracena, Arturo; Piel, Jean. (Comps.). Identidades nacionales y Estado moderno en Centroamérica. San José: Editorial Universidad de Costa Rica, 75-85.

Palmer, Steven. (1999). Adiós laissez-faire: la política social en Costa Rica (18801940). Revista de Historia de América, (124), 99-117.

Palmer, Steven. (2003). From popular medicine to medical populism. Doctors, Healers, and Public Power in Costa Rica, 1800-1940. Durham \& London: Duke University Press.

Pedraza Gómez, Zandra. (2004). El régimen biopolítico en América Latina. Cuerpo y pensamiento social. Iberoamericana, IV, (15), 7-19.

Pupo, Carlos. (1913). Nuestras enfermedades evitables. Principios de Higiene que nadie debe ignorar. San José: Imprenta Alsina.

Quesada Avendaño, Florencia. (2007). La modernización entre cafetales. San José, Costa Rica, 1880-1930. Tesis doctoral en Historia, Instituto Renvall, Universidad de Helsinki, Helsinki, Finlandia.

Quesada Avendaño, Gabriel. (2009, 9 de junio). Falsas afirmaciones sobre Víctor Quesada y Carmen Lyra. Semanario Universidad. Recuperado 7 de setiembre del 2013 de http://www.semanariouniversidad.ucr.cr/component/ content/article/292-Opini\%C3\%B3n/978-falsas-afirmaciones-sobre-victorquesada-y-carmen-lyra-.html

Quesada Soto, Álvaro. (1996). Identidad nacional y literatura nacional: de la "Generación del Olimpo" a la "Generación del Repertorio Americano". En Ortiz, María Salvadora. (Comp.). Identidades y producciones culturales en América Latina. San José: Editorial Universidad de Costa Rica, 209-239.

Quesada Soto, Álvaro. (2002). Uno y los otros. Identidad y literatura en Costa Rica (1890-1940). San José: Editorial Universidad de Costa Rica.

Rankin, Joanna C. (2009). The Role of Literature in the Context of Disability. Examination in partial fulfillment of the requirements of the degree of $\mathrm{PhD}$ in Critical Disability Studies at York University, Ontario, Canada.

Rodríguez Sáenz, Eugenia. (1998). Inventando el día de la madre en Costa Rica: 1890-1932. Reflexiones, (75), 33-42.

Rutenio. (2008a). No hay ideales. En García Monge, Joaquín; y Brenes Mesén, Roberto. (Eds.) Vida y Verdad. San José: Editorial de la Universidad Estatal a Distancia, 232-235. 
Rutenio. (2008b). Un símbolo. Marcelo. En García Monge, Joaquín; y Brenes Mesén, Roberto. (Eds.) Vida y Verdad. San José: Editorial de la Universidad Estatal a Distancia, 192-195.

Salas, Addy. (1998). Con Manuel. "Devolver al pueblo su fuerza". San José: Editorial Universidad de Costa Rica.

Sarasin, Philipp et al. (Eds.). (2007). Bakteriologie und Moderne. Studien zur Biopolitik des Unsichtbaren. 1870-1920. Frankfurt am Main: Suhrkamp.

Sarasin, Philipp. (2003). Infizierte Körper, kontaminierte Sprachen. Metaphern als Gegenstand der Wissenschaftsgeschichte. En Sarasin, Philipp. Geschichtswissenschaft und Discursanalyse. Frankfurt am Main: Suhrkamp, 191-230.

Solís Avendaño, Manuel. (2006). La institucionalidad ajena. Los años cuarenta y el fin de siglo. San José: Editorial Universidad de Costa Rica.

Trabajo. Un discurso que no se dijo frente a la tumba del Dr. Moreno Cañas (1938, 3 de setiembre). Trabajo, p. 3.

Zeledón, Joaquín. (1934). Crónica. Miasis quirúrgicas. Revista Médica, (5), febrero, 104-106.

Zeledón, Joaquín. (1935). La deformación atenuada y permanente del rostro. Revista Médica, (12), marzo, 284-293.

Ziemer, Gesa. (2008). Verletzbare Orte. Entwurf einer praktischen Ästhetik. Zürich-Berlin: Diaphanes.

Zumbado, Federico. (1896). Un caso de hernia del glans penis. Gaceta Médica, (5), 1 de setiembre, 147-148. 